\title{
You Are No Longer Just You: Netflix and the Evolution of Television
}

\section{Zoë Shacklock}

In January 2016, in a keynote address at the annual Consumer Electronics Show in Las Vegas, Netflix CEO Reed Hastings announced that the service had at that moment gone live in 190 countries around the world - 130 more than at the beginning of his speech. 'Today, right now,' Hastings dramatically announced, 'you are witnessing the birth of a global TV network - and I do mean the birth' (CES 2016). Emphasizing the global 'simultane[ity]' of the platform, he declared that 'whether you are in Sydney or St Petersburg, Singapore or Seoul, Santiago or Saskatoon, you can now be part of the Internet TV revolution.' Hastings's language here reflects the standard promotional rhetoric of the company - that Netflix creates something new, something innovative, something groundbreaking that takes one giant leap forward in the history of television.

Yet there is something of an oscillation between revolution and evolution in the discourses surrounding the platform, an uncertainty as to whether to frame its position in the television landscape through incremental change or dramatic upheaval. Two years later in 2018, Hastings moderated his language slightly, stating that Netflix was 'more evolutionary than revolutionary' (Turek and Moynihan 2018). Where YouTube can be understood as revolutionizing media production, he argued, in terms of user-generated content and open platforms, Netflix remains an evolution of television. Hastings is correct, of course - to argue that Netflix is a break with modes of television that came before is at best naïve and at worst wilfully ignorant. However, Hastings still believes that Netflix is an improvement on previous modes of television, stating that 'I would say we've very much improved television (Turek and Moynihan 2018). Here, he evokes the popular way in which evolution is deployed - as a natural pathway of progression towards some ideal fit, in which every step advances what came before. Indeed, in his keynote, Hastings began by setting up a historical trajectory from broadcast to cable to internet television, suggesting that 'each of these bring[s] a better experience'. Here, Hastings presents Netflix as the pinnacle of televisual development, and, consequently, as taking broad steps into the future.

The elements that Hastings pulls out to discursively frame the platform's global rollout - a magical moment of birth, a sense of simultaneity, and a connection between disparate cities across the world - all describe the flagship original programme Sense 8 as equally well as they do the platform, in which members of a cluster become attuned to one 
another in a 'birthing', and connections happen across eight different cities. The programme is invested in the exact same ideas of globality, simultaneity, connection, and moments of change as the platform itself. Interestingly, it also articulates an identical concept of 'evolution' as superior development. The sensates, or Homo sensorium, have a genetic mutation that facilitates their connection with one another. While Homo sensorium may ostensibly be a parallel branch of humanity, the narrative very much presents them as a superior form of humanity, in which they feel more intensely and form stronger connections than their Homo sapiens counterparts. Yet Sense8 also strongly resists teleological narratives of progress: it presents a mode of life that exists outside of linear connections and linear temporality, and it is interested in questions of empathy and connection, rather than simply the survival of the fittest. In this sense, Sense 8 seems to work through the conditions of its own platform, negotiating Netflix's features and promotional discourses in ways that act as a simultaneous reiteration and resistance.

Sense8 offers a lesson on how to approach Netflix in the age of streaming media, particularly in terms of its relationship to broadcast television. In this chapter I do want to position Netflix as something of an 'evolution' of television - but not as simply a step towards the future. In its original, Darwinian sense, evolution does not tell us anything about the future at all: the traces of evolution we see reveal the successful adaptations of the past, rather than pointing towards future change. In this sense, if Sense 8 negotiates the terrain between evolutionary and non-linear temporality, Netflix can and must be understood through how it negotiates foundational features of television, such as serial narration and serial consumption, temporality, liveness, and a sense of place. Graeme Turner and Anna Pertierra (2013), in their work on the local meanings and circulation of television, argue that too much of television studies is blinded by the newness of internet television. There is 'limited interest in examining the similarities, to the same extent as the differences', they argue, 'between the viewers' experience of consuming television via the box and via the computer' (2013: 10). Following Turner and Pertierra, I want to trace the continuities between these two evolutionary stages, rather than simply attending to the differences, and to argue that Netflix is as much in dialogue with televisual pasts as it is with televisual futures.

Sense8 also offers a way to interrogate Netflix's original programmes: to explore the extent to which they might reflect, or embody, or promote the features and conditions of the platform itself. All media texts bear the traces of the industrial conditions in which they are produced. Texts can also act as allegories, or narratives, of those very conditions - whether in direct support or in contradiction. In his work on the television landscape in the 2000s, 
Shawn Shimpach (2010) identifies an allegorical trend in serial television, in which programmes deliberately dramatize their own industrial conditions in order to normalize changes in the medium. Writing on mid-2000s programmes that emphasize the temporal and spatial agency of the white male hero, he suggests that these texts offer 'fantasies of transcendence, of temporal and spatial mobility that serve, almost allegorically, to underscore their very conditions of production and circulation' (2010: 9). Following Shimpach, I believe that Netflix programming, which also seeks to carve out a stable position in a rapidly changing television landscape, demonstrates a similar allegorical trend (albeit one with different identity politics). From Black Mirror: Bandersnatch's emphasis on interactivity and personalization, to Russian Doll's anxiety about temporal consumption, to Sex Education's infamous (and very deliberate) geographical confusion, Netflix's original programmes work through their own industrial conditions. They explore questions of time, of place, of agency, and of identity, narrativizing the very elements that structure debates and experiences of the platform itself.

Sense8 is a particularly crucial example here. The programme is one of the earliest of Netflix's original dramas and was promoted as an incentive to gather more subscriptions. Much was made of the high budget of the programme, with each episode costing approximately $\$ 9$ million dollars. Similarly, the presence of acclaimed auteurist (previously film) directors Lana and Lilly Wachowski, along with screenwriter J. Michael Straczynski, was positioned as a significant draw for new subscribers. Finally, the international scope of the programme was very attractive in both promoting the platform in new territories around the world, and in appealing to new subscribers in the West. Finance, authorship, and globality are all elements that Netflix presents as a source of distinction from broadcast television. They are also all things that arguably led to the series being cancelled after two seasons: its costly international scope, its appeal to international viewers who may have been pirating the programme (Spangler 2015), and the difficulties of realizing the Wachowskis' ambitious artistic vision. In this sense, Sense 8 may also point to the limitations of focusing entirely on the new at the expense of continuities with televisual pasts. Helen Piper astutely notes that despite the enthusiastic, at times hyperbolic language of both the industry and academics, she remains 'not convinced that the transformation [from broadcast to online television] is as absolute and complete' as the promotional rhetoric may tell us (2016: 173). It is my intention to similarly resist the transformative siren of streaming television, and to trace instead how streaming originals might continue to point to modes of television they seek to outpace. Sense8, I argue, narratively works through the tension between new and old industrial structures, narrative 
modes and consumption practices, offering an exploration of what we mean when we talk about both Netflix and television.

\section{Serial stories}

One of the most apparent ways in which Netflix distinguishes itself from broadcast television is through the seeming control and choice it offers the viewer. Rather than the fixed temporality and choices of the broadcast schedule, Netflix provides an on-demand service that can be consumed according to the pace and preference of the viewer. In Reed Hasting's CES keynote, he argues that Netflix fulfils a long-standing desire for agency on the part of the audience, emphatically declaring that while the DVD and VCR were "early efforts to give the people what they wanted', with Netflix, 'you don't have to sit through commercials, or be at the mercy of an 8pm tune-in. You just click and watch: a simple yet revolutionary shift from corporate to consumer control' (CES 2016). Again, we see clearly the ways in which Netflix's promotional rhetoric evokes ideas of revolutionary improvements on broadcast television; and again, we see the evolutionary discourse that positions the platform as the pinnacle of televisual progress. This dream of agency manifests clearly in Netflix's release strategy, in which whole seasons of programmes are 'dropped' at once (as opposed to the weekly release of broadcast television), so that a programme can be consumed according to the viewer's pace. Similarly, programmes are offered to viewers in horizontally organized categories, with thumbnails placed alongside one another within algorithmic categories such as 'Because You Watched', or taste groupings such as 'Gritty TV Dramas'. Here, the horizontal organization of the interface stands in contrast to the vertical construction of a TV schedule, emphasizing that all of these choices exist simultaneously at this moment of time. By offering a buffet of consumption to its viewers, rather than the staggered meals of broadcast television, Netflix presents itself as a progressive development of broadcast television.

Sense8 shares the same emphasis on plenty and the present as the platform itself, the same feeling of, to quote Marshall McLuhan, all-at-once-ness (McLuhan and Fiore 1967: 63). The programme is known for the recurring sequences in which all eight of the sensates share experiences, such as sex, dance, music, and celebrations: for example, the sex scenes in S01:E06 'Demons' and S02:E01 'Happy Fucking New Year', the karaoke scene in S01:E04, and the birthday celebration in S02:E01. Each of these sequences operate as a musical montage, and the impact of the sequences emerge from the choreographic spectacle of bodies moving with the music. In their focus on multiple bodies in different spaces and times united 
through kinetic movement, the sequences emphasize exuberance and simultaneity of experience. In S02:E01, the sensates celebrate their birthday, in a sequence that begins with all eight of the sensates blowing out Lito's candles together. Accompanied by Steve Aoki and Walk Off The Earth's 'Home We Go', we see a fast-paced montage of the sensates' birthday celebrations, in a kaleidoscope of colour and movement. The speed of the montage flattens out the temporality of the sequence, presenting everything as happening now, at once. The content of the sequence mirrors its formal excess: the sensates revel in excessive consumption of cake and whipped cream. In foregrounding the affects of simultaneous consumption, the sequence, and by extension, the programme itself, models the preferred consumption model of the interface - a splurge of all-at-once-ness.

Such an emphasis on abundant consumption is often framed (and, indeed, promoted) through the lens of dangerous excess, or the 'binge'. Marieke Jenner argues that while 'binge viewing' is not specific to Netflix, the platform has 'employed it more centrally' than others, and it remains a crucial part of its distribution strategy (2018: 110). It is also a key part of the Netflix interface: the 'autocue' function, which immediately starts playing the next episode during the credits of the previous one, encourages continuous viewing on the part of the audience. It is important to remember that continuous viewing has been part of the television landscape for decades - Raymond Williams' (1974) work on what he calls televisual flow shows how the broadcast schedule is arranged to maintain audience interest across an evening, or afternoon, of programming. Yet Netflix undoubtedly encourages marathon consumption: through the affordances of its interface, through its promotional tactics (its categories include 'Binge-worthy TV'), and also through the narrative structure of its original programmes, which are made to fit the affordances of the platform. Most episodes of Sense 8 end rather abruptly, and often on 'cliffhanger' moments, such as Kala fainting in S01:E05 'Art is Like Religion', the apparent suicide of Whispers in S01:E07 'W.W.N. Double D.', and Jonah's lobotomy in S02:E04 'Polyphony.' There are relatively few episodes that end in ways that aim to give the episode closure - S01:E04 'What's Going On', which ends with the triumphant conclusion of Nomi's hospital admission, is one of the few. In this, the episodes depart from the narrative structure that has dominated broadcast drama in the last three decades: what Jason Mittell terms narrative complexity, in which episodes both have some degree of closure and point onwards to the next episode (Mittell 2006: 32). Sense8's narrative structure thus fits the specific conditions of Netflix, and reflects the platform's aim to distinguish itself from broadcast television. 
Endings that resist closure are by no means new: the cliffhanger has been a staple of serial storytelling since its inception. However, I would argue that the cliffhanger functions somewhat differently in Netflix programming to broadcast television - and as such, continues to function as a form of distinction, or evolutionary marker. In broadcast television, an effective cliffhanger ends on a question, on a moment that leaves the narrative stakes precariously suspended. Jeremy Butler suggests that the soap opera cliffhanger leaves characters 'interrupted just as they are about to commit murder, discover their true paternity, or consummate a romance' (2012: 12). Here, the cliffhanger sets up 'will they/won't they' questions, leaving lives, loves, and identities hanging in the balance. Broadcast television cliffhangers must sustain interest and debate over a period of time between instalments (whether a week, months, or simply a commercial break), and so need to pose questions that inspire debate and imagination. Netflix cliffhangers, in contrast, simply need to prevent us from exiting the stream. Sense8's cliffhangers tend to occur just after a pivotal action has occurred. Two key examples here are the suicide of Nigel Bolgers in S101:E07, and Lito's attempted suicide in S01:E09 'Death Doesn't Let You Say Goodbye'. Both of these episodes end after the gunshot, leaving no doubt as to whether a life remains at risk. After Lito narrowly avoids shooting himself, what prompts us to cue up the next episode is not the question of his life, but our affective entanglement with his emotions. Similarly, after Bolgers dies, the episode ends abruptly with a close up of Nomi and Amanita's weeping faces: here, we are drawn along in the undercurrent of Nomi and Amanita's shock and relief, rather than an unfinished plot point. Michael Newman suggests that in broadcast television, cliffhangers employ 'highly focused questions' that direct the main plot of a particular episode (2006: 20). In Netflix programming, I would argue, these questions tend to be generalized questions about emotion and reaction, constructing an affective undertow that carries viewers into the next episode. Netflix's stream, then, is an affective one.

These questions of affective entanglement are also narrative concerns for many of Netflix's original programmes. Casey McCormick, in her work on House of Cards, suggests that the programme places a 'thematic emphasis on addiction, power and bodily exhaustion' in order to reflect the physical and mental experience of marathon viewing (2016: 105). Following McCormick, we can see how Sense 8 might similarly place a thematic emphasis on the experience of its marathon viewing - in this case, intense emotional connection. The connection between the sensates is an open affective bond, in which emotions and experiences are shared freely and smoothly throughout the cluster. There are no boundaries between the sensates, much in the same way that Netflix aims to lower the boundaries between episodes 
themselves, instead constructing a smooth affective flow. The structure of feeling between the sensates models the same structure of feeling the Netflix interface encourages between audience and cliffhanger: one of emotional, affective entanglement. Such emotional sharing is, of course, the key feature that distinguishes Homo sensorium from Homo sapiens. Yet within the programme, this difference between the two evolutionary strands is presented in terms of value and quality. In SE2:E02 'Who Am I?', Nomi and Amanita attend a university lecture by Professor Kolovi, an academic who had previous posited the existence of Homo sensorium. In his lecture, Kolovi suggests that early human ancestors such as the Neanderthals and Denisovans were killed in a 'genocide' by Homo sapiens. Here, he echoes an earlier comment from villain Whispers, who describes Homo sapiens as 'more violent, intolerant and possessive than any species in the history of the planet.' The implication is that Homo sensorium, as possessing a greater capacity for empathy, might be an improvement on the violent, intolerant Homo sapiens. In a direct echo of Netflix's own promotional rhetoric, evolution is not just a random matter of chance, but a search for a pinnacle, superior form of existence. Sense8, in working through these questions of consumption and affect and experience, cannot entirely divorce itself from the discourses of quality that the platform itself promotes.

It is important to remember that 'binge viewing' is not an invention of either Netflix or streaming platforms: fan communities have engaged in marathon viewing practices for decades (Stevens, forthcoming), and the packaging of television into DVD box sets in the 2000s also encouraged marathon consumption (Brunsdon, 2010). It is also important to remember that television has always been understood as a medium of the present moment, namely through its focus on live transmission (which I will discuss later in this chapter), and its ability to conflate different temporal modalities together (Caldwell, 1995). And television has always promised emotional connection, aiming to foster what Karen Lury terms a 'common culture of empathy' (2011: 201). In this sense, Sense8 (and Netflix more generally) continues to point back to the things that television has always promised us, even while negotiating the demands and rhetoric of the digital platform. Sense 8 works through the implications of contemporary media consumption, narratively exploring issues of time, pace, and affect in ways that emphasize both foundational features of television and their reconfiguration in the Netflix interface.

\section{Liveness and simultaneity}


Sense 8 effectively presents a vision of community, a global network of people connected by shared empathy and emotional experience. This dream of a global, empathic community can be read as a direct response to the seeming fragmentation of community in the post-broadcast era. For much of the history of broadcast television, programmes were broadcast as they were recorded, meaning that television became understood as a 'live' medium. While scholars such as Jane Feuer (1983) have rightly argued that television's 'liveness' is an ideological construction more than an essential component of the medium, liveness continues to function as a signifier of the televisual - of what television is and what it, uniquely, can do. This largely operates through what we can call co-presence, or the way in which liveness allows members of an audience to feel connected: across a country or a region, all members of the audience watch a programme at the exact same time. As John Ellis says, broadcasting facilitates a feeling of community, 'a sense that others, anonymous though they may be, are sharing the same moment' (2000: 75). Post-broadcast television, in contrast, seemingly shatters this sense of 'co-presence'. When an entire season of a programme is released all at once (as per the Netflix model), it can be watched according to an individual viewer's preferred pace and time. The Netflix audience, then, may lack a sense of being part of a simultaneous, copresent viewing community.

However, Nick Couldry (2004) argues that 'liveness' is a concept with broader cultural significance, which needs to be detached from its tight connection with broadcast media. He suggests that 'liveness' shifts to adapt to new cultural forms: with the rise of the internet and mobile forms of media, we see multiple nodes of simultaneous communication and connection rather than a single, central, mode of transmission (2004: 356). Couldry identifies two key modes: firstly, 'online liveness', in which online spaces create clusters of liveness across multiple sites and platforms, which exist in parallel with one another but do not necessarily intersect. Secondly, he identifies 'group liveness', in which a social group can remain in constant contact with one another through digital technology. With a smartphone in your pocket, you can take your social circle with you no matter where you travel, hence maintaining a constant sense of co-presence. Both of these forms of liveness lack a single 'institutional "centre" of transmission', as Couldry suggests, but they still act as means of 'coordinating communications and bodies across time and space which, like "liveness" proper, involve (more or less) simultaneity' (2004: 356). In this sense, we can see that while it may take different forms, the cultural currency of liveness persists into the digital age and is extended geographically. 
There are clear similarities with streaming audiences. As I suggested earlier, streaming platforms do not offer the same kind of co-presence as broadcast television - the sheer number of offerings and the temporal flexibility of the platform mean that audiences lack a central structure of co-presence. However, streaming audiences may still possess feelings of simultaneity, or of belonging to a viewing audience of a particular programme, albeit one that is slightly more fragmented across both time and space. Such structures of feeling are encouraged by the Netflix interface itself. Categories of 'Popular on Netflix', 'Trending Now' and 'Top 10 in [country] Today' all allude to the presence of a larger community of viewers. These categories deliberately emphasize simultaneity through their focus on the present temporal moment - these programmes are being watched 'now' and 'today', fostering some semblance of co-presence. However, it is important to remember that these categories are tailored to individual viewers - my 'Trending Now' category is not what is trending on Netflix overall, but amongst people with similar viewing histories to me. In this sense, the co-presence facilitated by Netflix is more akin to the multiple clusters of 'online liveness' that Couldry proposes, in which there are multiple, parallel bubbles of somewhat co-present viewers. Of course, this is not to suggest that liveness is the only means through which Netflix texts become meaningful to audiences - many Netflix originals have active and invested fan audiences that value repeated viewings. Yet it is clear that liveness retains some form of cultural cachet, as it remains a valuable experience that Netflix continues to embed within its interface, even if it takes a slightly different form to the more traditional understanding of the term.

These new ideas of liveness - as multiple. parallel, and transportable - are also akin to the structure of relation between the sensates. When Couldry suggests that digital technologies allow individuals to remain 'continuously co-present to each other even as they move independently across space' (2004: 357), he could equally be describing the connections between the sensates themselves. In the mythology of Sense8, there are three main abilities: visiting, sharing, and psychic connection. All of these abilities offer a sense of co-presence, in which the sensates experience time, space, language, and physicality in a simultaneous fashion. Yet all of these experiences remain mediated, in that the sensates do not physically travel to other places, and remain aware of their own bodies and of their own locations. The connections between the sensates thus act as a form of mediated co-presence, in which the sensates are geographically isolated from one another but possess a feeling of simultaneous existence. And importantly, these experiences operate in parallel, smaller configurations as much as singular ones: the sensates share and visit in parallel configurations of pairs and 
threes, not just as the whole cluster. These mediated, fragmented, and granular forms of copresence directly model the 'liveness' experienced by the Netflix audience, who experience overlapping connections with others while remaining within their own spatiotemporal sites.

As I suggested earlier in this chapter, the programme foregrounds its spectacular group sharing/visiting scenes. However, throughout the two seasons, the most common connection scenes happen between pairs of sensates in moments of quiet conversation, not the group as a whole. In a particularly moving example from S01:E09 'Death Doesn't Let You Say Goodbye', Nomi and Lito 'visit' one another as the latter sits in the Diego Rivera museum in Mexico City, in front of sketches of Rivera's Man at the Crossroads mural. The two discuss their shared experiences of queerness, desire, fear, and shame. Throughout the scene, the location swaps between the museum and Nomi's living room in San Francisco, and the camera helps construct a spatial differentiation between the two locations, placed in front of the pair in the museum and behind them in the living room. By depicting two individuals in individual spaces, brought together in a shared experience, the scene depicts the mediated copresence that defines liveness. In the following episode, we see a similar sequence between Kala and Capheus, who watch Van Damme's Lionheart (Lettich, 1990) together. Again, the sequence focuses on two characters sitting side-by-side, connecting through their shared desire to move beyond the limitations of their own lives. While this sequence does not interweave the two locations - it begins with Kala on a park bench in Mumbai, and then shifts smoothly to Capheus's couch in Nairobi - it again emphasizes the way in which they remain both within their own spaces and times, and also that of their companion.

While there are many similar scenes throughout Sense8, I have drawn attention to these two specifically for what they have to offer our understanding of the programme's industrial allegory. Both sequences deliberately present their characters connecting while seated in front of a form of art - Rivera's Man at the Crossroads, and Van Damme's Lionheart. Both sequences pair domestic space with public space, and both organize the 'visit' specifically around the media object - we spend more time with Rivera and Lionheart than we do in Nomi and Kala's locations. As such, the sequences offer a direct presentation of the co-presence promoted by Netflix: individuals in individual spaces and on individual couches, across public and private spaces, brought together in shared experiences that cohere around a particular media text. Once again Sense 8 narrativises the conditions and experiences of its own platform, through an emphasis on co-present communities that intersect in mediated, yet connected, ways. The message seems to be that, no matter where (or when) an individual might be, there is always a connection to be found in front of the screen. The programme thus 
presents a new model of community, and in particular, viewing communities, in the Netflix era.

I have also focused on these two sequences for what they tell us about Netflix's relationship to broadcast television. It is important not to lose track of these ordinary scenes of companionship, particularly in a programme that places a large emphasis on corporeal spectacle. And it is important to remember what they say about foundational televisual pleasures of community and belonging. As I suggested earlier, it is well-established within television studies that liveness is more an ideological structure of television than a purely technological or ontological one. Yet it is one that Netflix may have inherited, through the platform's focus on promoting structures of co-presence and mediated community. Netflix is not a complete break with models of broadcast television, but continues to draw from its foundational features: as Ramon Lobato reminds us 'Netflix may still feel like TV to viewers, and it relies on this familiar pleasure for its success' (2019: 34). To return to the evolution narrative at the heart of both the platform and the programme, Sense 8 presents an evolution of community and human connection, one that is both more fragmented yet all the more connected because of it. By working through the parameters of televisual liveness and co-present communities, the programme interrogates how both liveness and the 'televisual' continue to function in the age of streaming media.

\section{Reaching for the world}

Of course, the co-present community in Sense8 is not a local group, or even a national community, but precisely a global one. The eight sensates are located in eight different cities across Europe, Asia, Africa, and North America. The programme was filmed in these different cities as a measure of authenticity, and while the majority of the dialogue is in English, there are moments of multilingualism. Sense 8 is very clearly about global connection, and in particular, about the universal experiences that we share no matter where we live - emotion, desire, sex, and love. And in this way the programme is very clearly, once again, a narrative of its own industrial conditions - it is not hard to see why Netflix may have chosen a programme with such a global imagination for one of its first originals, a programme that is so obviously about transnational connection and global connection. As a so-called 'global' medium, Netflix promises both universality and diversity: transforming global distribution flows so that texts are accessible at the same time in every place; and widening access to a broader range of world media. Ramon Lobato notes that 'global simultaneity' is a distinctive feature 
of Netflix, particularly in contrast to historical (and more sequential) patterns of global distribution (2019: 69). Similarly, Marieke Jenner argues that the Netflix audience is 'not simply an accumulation of 'fragments' of different national audiences', but a transnational collective that operates across multiple zones of consumption (2018: 251). Once again, Sense8 narrativizes the particular aims and affordances of Netflix - in this case, its presentation as a global platform.

Sense8's opening credits offer a visual depiction of this global ambition. Jonathan Gray describes title sequences as 'offering "proper interpretations" of genre and character', suggesting that their repetition works to 'reaffirm what a show is about, how its characters are related, and how we "should" make sense of them' (2010: 74-6). Sense8's opening credits work on a double level, affirming not just the concerns of the programme, but also those of its platform itself. The credits consist of a rapid montage of people and places around the world, beginning with slower-paced wide shots of the eight cities featured in the programme, then gradually transitioning to rapid close-ups that depict people and scenes of everyday life. Designed by Karin Winslow Wachowski, the sequence can be read as an exhilarating kaleidoscope of people and places, and a multicultural, queer vision of the world. The credits clearly reiterate the programme's message of universality in diversity, or the celebration of both difference and commonality. Yet the sequence is also overwhelmingly an experience of movement: almost every shot contains movement, whether of the camera, the natural world and weather, transportation, or the movement of people. It is here, I would argue, that we can identify another parallel between the programme and the platform: the credits mirror the experience of the Netflix interface itself. In her work on media interfaces, Lisa Parks conceptualizes the interface as a 'kinetic screen', arguing that the predominant experience of an interface is one of movement: scrolling, surfing, browsing, and so on (2003: 54). We see this clearly in the Netflix interface, which consists of content moving at different scales, from thumbnails we scroll through to the trailers that begin to play when we hover over them. In terms of the qualities of the kinetic experience, this flurry of movement at different speeds and scales mirrors what we see in the Sense 8 credits. These credits can be read as a rapid scan through a catalogue of experiences and places, almost a browsing, perhaps, of the world. Both Netflix and Sense 8 thus promise a feeling of travel through a cornucopia of image and stories across the world, and the structure of feeling embedded in the Netflix interface - of the multiplicity and kineticism of the world presented for our consumption - is identical to that in the Sense 8 opening credits. 
This vision of global universality is, of course, a somewhat utopian dream. Both Sense8 and Netflix aim for global reach, yet continue to struggle to truly transcend the national. Ramon Lobato presents a very thorough analysis of the ways in which Netflix remains locally specific, from its catalogue to its regulatory functions. As he says, Netflix may be global but it 'does not envelop the world evenly', remaining caught by local content regulations and national distribution agreements, which control what the platform can host (2019: 71). The content that can be distributed globally is, of course, the platforms originals, which are dominated by American productions. Sense8's global scope can be understood as similarly uneven. In a widely-circulated blog post for Nerds of Colour, Claire Light suggests that the programmes' 'depiction of life in non-western countries is built out of stereotypes, and...suffused with tourist-board clichés' (2015). Both platform and programme may promise to give us access to the world, but this continues to operate through a Hollywood-tinted glasses. Indeed, both Sense8 and Netflix have specifically been criticized over the question of monolingualism. Despite sharing an outward looking dream of a global community (and a global catalogue), the English language remains by far the automatic and dominant presentation. Cáel M. Keegan notes that the programme's utopian image of global connectivity is 'softened by the prosthetic use of English', thus catering overwhelmingly to the comfort zones of Anglophone viewers (2016: 609). For while the sensates converse with one another in different languages, and occasionally show moments of self-reflexive knowledge of their multilingualism, the narrative always presents their psychic link in English. There are pragmatic reasons for this - namely the costs of dialect coaches and translation services in an already expensive programme - but the message is clear: if the sensates draw attention to the universality of experience and emotion, then they also imply that English is the universal language. An identical kind of linguistic dominance happens at the level of the interface itself. In a Variety exposé on the 'secrets' of Netflix, it emerged that Netflix deliberately presents nonEnglish programmes (such as the German drama Dark and the Brazilian science fiction 3\%) in their dubbed format to Western audiences, rather than their original language with subtitles (Roettgers 2018). Despite audiences stating during consumer testing that they preferred subtitles, Netflix's own data suggested that viewers were more likely to finish dubbed series. Just like Sense8, then, Netflix itself continues to suggest that moments of transcultural encounter require English translation. The fact that the very same critique is levelled at both the narrative programme and the platform to which it belongs furthers my argument: the two can be read as invested in similar values, properties, and aims. 
Of course, it is too simple to suggest that with the rise of Netflix, television suddenly becomes 'global'. As the quintessential 'window on the world', television has always been a source for popular knowledge about the world, and as the archetypal 'global village', television has always promised to bring the whole world together within the intimate ties of community and belonging. Netflix's aim towards the global, while ostensibly a means of distinguishing itself from ordinary, 'national' television, is thus simultaneously an extension of television's promise to act as a window on the world. Yet television's global reach has always been something of an imperfect one. The history of global television is one in which international exports are localized and distribution flows are uneven, suggesting that the medium continues to be particularly meaningful at a national and local level. Lobato astutely points out that Netflix follows the same pattern as earlier 'revolutionary' television services such as cable: a push towards global universality, and a pull back towards the value of local specificity (2019: 63). Sense8's uneven reach towards globality again demonstrates how the programme negotiates its position between the industrial models of streaming television, and the legacy of broadcast television.

To return to Hastings's CES keynote, the event marked the debut of a promotional trailer celebrating Netflix's global rollout. The trailer consists of a montage of clips from its various programmes, including Sense8, edited together into an uplifting message of community and togetherness. Here, Netflix turns to its own storytelling in order to communicate its own values and qualities, suggesting that its storytelling is, in effect, a story of the platform itself. Yet too often, the stories that Netflix tells of itself remain one-directional stories, focused on emphasizing its difference and its novelty, and a linear evolutionary narrative of progress. It is important to tell a different story: to continue to read Netflix as part of the history of television, and to continue to understand it through the foundational features of the medium. Sense 8 offers a key lesson here. It does gesture toward the future of audio-visual media, through its emphasis on different configurations of serial storytelling, its reconfiguration of liveness, and its reach for global address. And it simultaneously shows us what television has always done and what it has always offered its audience, whether the promise of emotion, of the present, of liveness, of community, or of access to the world. These properties may look somewhat different in the age of streaming television, yet they remain part of a continuity of television history, rather than a mode of experience to be entirely left behind in leaps and bounds. And this is what Sense 8 ultimately tells us, in the programme's reminder that difference is less important than the threads of commonality that bind the world together. 


\section{Bibliography}

Brunsdon, C. (2010), 'Bingeing on Box-Sets: The National and the Digital in Television Crime Drama', in J. Gripsrud (ed.), Relocating Television: Television in the Digital Context, 63-75, Abingdon: Routledge.

Butler, J.G. (2012), Television: Critical Methods and Applications, New York: Routledge.

Caldwell, J.T. (1995), Televisuality: Style, Crisis and Authority in American Television, New Brunswick, NJ: Rutgers University Press.

CES (2016), 'Reed Hastings, Netflix - Keynote 2016', YouTube, 7 January. Available online: https://www.youtube.com/watch?v=15R3E6jsICA\&t=196s (accessed 25 May 2020).

Couldry, N. (2004), 'Liveness, "Reality," and the Mediated Habitus from Television to the Mobile Phone, The Communication Review, 7 (1): 353-361.

Ellis, J. (2000), Seeing Things: Television in the Age of Uncertainty, London: I.B. Tauris.

Feuer, J. (1983), 'The Concept of Live Television: Ontology as Ideology', in E.A. Kaplan (ed), Regarding Television: Critical Approaches - an Anthology, 12-22, Frederick, MD: University Publications of America.

Gray, J. (2009), Show Sold Separately: Promos, Spoilers, and Other Media Paratexts, New York: New York University Press.

Jenner, M. (2018), Netflix and the Reinvention of Television, Cham, Switzerland: Palgrave MacMillan.

Keegan, C.M. (2016), 'Tongues without Bodies: The Wachowskis' Sense8', Transgender Studies Quarterly, 3 (3-4): 605-610. 
Light, C. (2015), 'Sense8 and the Failure of the Global Imagination', Nerds of Color, 10 June. Available online: http://thenerdsofcolor.org/2015/06/10/sense8-and-the-failure-ofglobal-imagination (accessed 25 May 2020).

Lobato, R. (2019), Netflix Nations: The Geography of Digital Distribution, New York: New York, University Press.

Lury, K. (2011), 'The Loss of the Contingent in Digital Television', in J. Bennnett and N. Strange (eds), Television as Digital Media, 181-203, Durham: Duke University Press.

McCormick, C. (2016), 'Forward Is the Battle Cry”: Binge-Viewing Netflix's House of Cards, in K. McDonald and D. Smith-Rowsey (eds), The Netflix Effect: Technology and Entertainment in the $21^{\text {st }}$ Century, 101-116, New York: Bloomsbury.

McLuhan, M. and Fiore, Q. (1967), The Medium is the Massage: An Inventory of Effects, London: Penguin.

Newman, M. Z. (2006), 'From Beats to Arcs: Toward a Poetics of Television Narrative', The Velvet Light Trap, 58, 16-28.

Parks, L. (2004), 'Kinetic Screens: Epistemologies of Movement at the Interface', in N. Couldry and A. McCarthy (eds), Mediaspace: Place, Scale and Culture in a Media Age, 3757, Abingdon, Oxon: Routledge.

Piper, H. (2016), 'Broadcast Drama and the Problem of Television Aesthetics: Home, Nation, Universe', Screen, 57 (2): 163-83.

Roettgers, J. (2018), 'Netflix’s Secrets to Success: Six Cell Towers, Dubbing and More', Variety, 8 March. Available online: https://variety.com/2018/digital/news/netflix-success-secrets-1202721847/ (accessed 25 May 2020).

Shimpach, S. (2010), Television in Transition, Malden: Wiley-Blackwell, 2010. 
Spangler, T. (2015), 'Netflix 'Sense8' Thriller from Wachowskis Pirated More Than 500,000

Times Since Debut', Variety, 8 June. Available online: https://variety.com/2015/digi-

tal/news/netflix-sense8-piracy-wachowskis-1201514526/ (accessed 16 June 2020).

Turek, A. and Moynihan, R. (2018), 'Netflix's Reed Hastings Tells Business Insider Why he Doesn't Care about the Cannes Film Festival ', Business Insider, 27 April. Available online: https://www.businessinsider.com/head-of-netflix-we-have-improved-television-2018$\underline{4 ? \mathrm{r}=\mathrm{UK}}$ (accessed 16 June 2020).

Turner G. and Pertierra, A.C. (2013), Locating Television: Zones of Consumption, Abingdon: Routledge.

Williams, R. (1974), Television: Technology and Cultural Form, London: Fontana. 